\title{
INSIDENSI TB PARU KASUS BARU PADA PASIEN DENGAN DM TIPE 2 DI SALAH SATU RUMAH SAKIT SWASTA CIKAMPEK
}

\author{
Himyatul Hidayah*, Surya Amal \\ Fakultas Farmasi, Universitas Buana Perjuangan Karawang \\ *himyatul.hidayah@ubpkarawang.ac.id \\ Surya.amal@ubpkarawang.ac.id
}

\begin{abstract}
Abstrak
Penyakit tuberkulosis (TB) merupakan penyakit menular yang disebabkan oleh Mycobacterium tuberculosis, menjadi penyakit infeksi penyebab kematian kedua di dunia setelah HIV-AIDS. Prevalensi kejadian TB di Indonesia menempati urutan ketiga setelah India dan China. Diabetes mellitus diperkirakan penyebab $15 \%$ kasus tuberkulosis saat ini, karena penyakit diabetes mellitus dapat merusak pertahanan host. Tujuan penelitian ini untuk mengetahui insidensi TB paru kasus baru dengan DM tipe 2 di salah satu rumah sakit swasta Cikampek. Instrumen penelitian yang digunakan adalah data sekunder rekam medik pasien TB paru kasus baru yang menjalani rawat jalan selama bulan April - September 2017 di Poli Penyakit Dalam salah satu rumah sakit swasta Cikampek. Hasil penelitian ini menunjukkan bahwa dari 83 pasien TB paru kasus baru terdapat 26 pasien TB paru kasus baru dengan DM Tipe 2. Frekuensi TB paru kasus baru dengan DM tipe 2 lebih banyak pada kelompok jenis kelamin perempuan $(53,85 \%)$, usia $>54$ tahun $(65,39 \%)$, hasil pemeriksaan BTA sputum negatif $(61,50 \%)$, lamanya pengobatan yang dianjurkan $>8$ bulan $(53,85 \%)$. Disimpulkan bahwa insidensi tuberkulosis paru kasus baru dengan DM tipe 2 rawat jalan di Poli Penyakit Dalam salah satu rumah sakit swasta Cikampek selama bulan April - September 2017 adalah sebesar $31,33 \%$.
\end{abstract}

Kata Kunci: Insidensi, Tuberkulosis paru, Diabetes mellitus tipe 2

\begin{abstract}
Tuberculosis (TB) is an infectious disease caused by mycobacterium tuberculosis, it became the second leading cause of death in the world after HIV-AIDS. The prevalence of incidence of TB in Indonesia ranked third after India and China. Diabetes mellitus thought to be the cause $15 \%$ the case of tuberculosis at the present time, due to disease of diabetes mellitus can be damaging to defense host. The purpose of this study was to know the incidence of new cases of pulmonary TB with type 2 diabetes mellitus in one of the private hospital Cikampek. The research instrument used was secondary data from the medical records of new TB pulmonary outpatients during April - September 2017 in the polyclinic internal medicine in one of the private hospital Cikampek. The result of study indicate that of the 83 new cases of pulmonary tuberculosis patients there were 26 new cases of pulmonary tuberculosis patients with type 2 diabetes mellitus. The frequency of pulmonary tuberculosis a new case with type 2 DM be greater among a group of the female sex (53,85\%), the age of $>54$ years (65,39\%), results smear sputum negative (61,50\%), length of treatment recommended $>8$ months $(53,85 \%)$. It was concluded that the incidence of new cases of pulmonary $T B$ with type 2 diabetes mellitus outpatients care in one of the private hospital Cikampek during the month of April - September2017 was recorded at 31,33\%.
\end{abstract}

Keywords: Incidence, Pulmonary tuberculosis, Type 2 diabetes mellitus 


\section{PENDAHULUAN}

Tuberkulosis (TB) adalah salah satu penyebab utama kematian diantara penyakit menular di seluruh dunia. Pada tahun 2012 sekitar 8,6 juta orang mengembangkan TB dan 1,3 juta meninggal karenanya. Perlu dikemukakan bahwa 2 miliar orang terinfeksi Mycobacterium tuberculosis merupakan deposit patogen yang substansial. Oleh karena itu ada beberapa tantangan bagi pemegang otoritas untuk menghilangkan TB sampai tahun 2050. Studi menunjukkan bahwa faktor budaya, lingkungan, dan sosio-politik merupakan penentu dalam proses ini (Moreira de Freitas, I et al, 2015). Sejak tahun 1993, WHO menyatakan bahwa tuberkulosis (TB) merupakan kedaruratan global bagi kemanusiaan. Walaupun strategi DOTS telah terbukti sangat efektif untuk pengendalian TB, tetapi beban penyakit TB di masyarakat masih sangat tinggi. Dengan berbagai kemajuan yang dicapai sejak tahun 2003, diperkirakan masih terdapat sekitar 9,5 juta kasus baru TB, dan sekitar 0,5 juta orang meninggal akibat TB di seluruh dunia (WHO, 2009). Sementara data penderita TB di Indonesia menunjukkan bahwa penyakit tuberkulosis (TB) masih merupakan masalah kesehatan yang serius dan menunjukkan adanya peningkatan kasus dari tahun ke tahun (Kementerian Keseharan RI, 2014).

Kejadian TB paru aktif diperkirakan sekitar 8 (delapan) juta kasus baru per tahun di seluruh dunia dan penyebab kematian sekitar 2 juta per tahun (Banu et al, 2006). Pada tahun 2009, ada 9,4 juta kasus insiden TB global yang setara dengan 137 kasus per 100.000 penduduk. Sebagian besar jumlah kasus pada tahun 2009 terjadi di Asia (55\%) dan Afrika (30\%); proporsi kasus yang lebih kecil terjadi di Mediterania Timur (7\%), wilayah Eropa (4\%) dan Amerika (3\%) (WHO, 2010). Di Indonesia penyakit tuberkulosis (TB) masih merupakan masalah kesehatan yang serius dan menunjukkan adanya peningkatan kasus dari tahun ke tahun (Kementerian Keseharan RI, 2014). Berdasarkan data Riset Kesehatan Dasar (RISKESDAS) Kementerian Kesehatan RI 2013 bahwa prevalensi penduduk Indonesia yang didiagnosis TB paru oleh tenaga kesehatan tahun 2013 adalah 0.4 persen, tidak berbeda dengan 2007. Lima provinsi dengan TB paru tertinggi adalah Jawa Barat (0.7\%), Papua (0.6\%), DKI Jakarta (0.6\%), Gorontalo (0.5\%), Banten (0.4\%) dan Papua Barat (0.4\%). Profil Kesehatan Provinsi Jawa Barat Tahun 2012 menunjukkan data penderita TB di 
Kabupaten Karawang dengan jumlah kasus baru 2.821, kasus lama 42 dengan prevalensi 129 kasus per 100.000 penduduk (Kementerian Kesehatan RI, 2013).

Survei nasional tentang prevalensi penyakit TB di Indonesia telah berhasil dilaksanakan pada tahun 2013/2014 di bawah kepemimpinan Program TB Nasional dan Institut Penelitian dan Pengembangan Kesehatan Nasional. Tujuan utama survei ini adalah untuk memperkirakan prevalensi TB paru diantara populasi umum berusia $\geq 15$ tahun. Dari survey tersebut menunjukkan bahwa beban penyakit TB di Indonesia jauh lebih tinggi dari perkiraan sebelumnya. Angka yang direvisi untuk tahun 2013 adalah perkiraan tingkat kejadian TB 403 (kisaran, 278-550) per 100.000 penduduk dan perkiraan prevalensi (semua jenis TB, dan termasuk anak-anak dan orang dewasa) 660 (kisaran, 523-813) per 100.000 penduduk (WHO, 2015). Pola kebiasaan yang dihubungkan dengan kejadiaan TB seperti yang telah dipaparkan di atas, juga terdapat penyakit penyerta terkait gaya hidup yang kini banyak mendapat perhatian peneliti yakni DM. Sementara komplikasi TB dengan penyakit DM juga menunjukkan perhatian sebagaimana penelitian Kottarath, M.D et al (2015) yang melaporkan 19,6\% penderita TB komplikasi DM. Menurut Girardi et al.(2017) diabetes melitus (DM) adalah penyakit epidemi global yang memengaruhi negara maju maupun negara berkembang, dan sekitar 15\% pasien TB memiliki komorbiditas dengan diabetes.

Data WHO menunjukkan bahwa DM akan meningkatkan risiko infeksi tuberkulosis (TB) tiga kali lebih besar dibandingkan populasi normal dan meningkatkan risiko reaktivasi TB pada TB laten. Penderita TB dengan diabetes juga lebih sering gagal dalam pengobatan dan lebih sering kambuh dibandingkan penderita TB tanpa diabetes sehingga meningkatkan risiko untuk terjadinya multi drug resistance (MDR)TB (Suyono S, 2011). Penelitian yang dilakukan Alisjahbana dkk di Indonesia menunjukkan bahwa prevalensi DM pada penderita TB adalah 14,8\% dibandingkan 3,2\% pada populasi normal. TB paru aktif akan lebih sering muncul pada pasien DM yang tergantung insulin (insulin dependent diabetes mellitus/IDDM) dibandingkan dengan pasien DM tidak tergantung insulin (non insulin dependent diabetes mellitus/NIDDM). Pasien TB paru dengan diabetes mengalami hasil pengobatan TB yang lebih buruk, tingkat kekambuhan yang lebih tinggi setelah pengobatan tuberkulosis, dan risiko kematian yang lebih tinggi dari TB dibandingkan dengan pasien tuberkulosis saja. Diabetes dan tuberkulosis sering terjadi secara bersamaan 
dan saling menyulitkan untuk pengobatan di berbagai tingkatan. Suatu penelitian melaporkan bahwa prevalensi pasien DM yang mengalami TB di Indonesia adalah sebesar 12,8\% - 42\% (Sanusi H, 2006). Angka kejadian DM di Indonesia semakin meningkat, demikian juga angka kejadian TB paru di Indonesia juga masih sangat tinggi. Penurunan imunitas pada pasien DM dapat meningkatkan risiko infeksi TB paru. Berdasarkan hal tersebut, maka perlu dilakukan penelitian untuk mengetahui insidensi TB paru kasus baru pada pasien DM tipe 2 di Poli Penyakit Dalam salah satu rumah sakit swasta Cikampek Kabupaten Karawang dan distribusi frekuensinya berdasarkan jenis kelamin, usia, hasil pemeriksaan BTA sputum dan lamanya pengobatan yang dianjurkan.

\section{METODE PENELITIAN}

Penelitian dilakukan di Poli Penyakit Dalam salah satu rumah sakit swasta Cikampek Kabupaten Karawang terhadap pasien TB paru kasus baru yang menjalani rawat jalan selama bulan April - September 2017. Instrumen penelitian yang digunakan adalah data sekunder rekam medik pasien TB paru kasus baru. Populasi penelitian ini adalah seluruh pasien yang didiagnosis sebagai penderita tuberkulosis paru kasus baru yang menjalani rawat jalan di Poli Penyakit Dalam di salah satu rumah sakit swasta Cikampek selama bulan April - September 2017. Kasus baru pada penelitian ini adalah semua pasien yang baru terdiagnosa TB paru dan menjalani terapi maksimal 1 bulan.

Sampel penelitian ini adalah pasien TB paru kasus baru dengan DM tipe 2 yang memenuhi kriteria inklusi. Analisis dilakukan terhadap distribusi frekuensinya berdasarkan jenis kelamin, usia, hasil pemeriksaan BTA sputum dan lamanya pengobatan yang dianjurkan. Distribusi frekuensi serta insidensi TB paru kasus baru dengan DM tipe 2 pada penelitian ini dinyatakan dengan persentasi.

\section{HASIL DAN PEMBAHASAN}

\section{Hasil Penelitian}

Penelitian yang dilakukan di Poli Penyakit Dalam di salah satu rumah sakit swasta Cikampek didapatkan 83 pasien TB paru kasus baru berdasarkan rekam medik selama periode penelitian. 
Tabel 1. Distribusi pasien TB paru kasus baru yang menjalani rawat jalan di Poli Penyakit Dalam salah satu rumah sakit swasta Cikampek selama April - September 2017 dengan DM tipe 2 dan tanpa DM tipe 2

\begin{tabular}{llc}
\hline \multirow{2}{*}{ DM Tipe 2 } & \multicolumn{2}{c}{ TB Paru Kasus Baru $(\mathrm{n}=83)$} \\
\cline { 2 - 3 } & $\mathrm{n}$ & $\%$ \\
\hline$(+)$ & 26 & 31,33 \\
\hline$(-)$ & 57 & 68,67 \\
\hline Total & 83 & 100 \\
\hline
\end{tabular}

Tabel 1 memperlihatkan gambaran distribusi pasien tuberkulosis paru kasus baru dengan DM tipe 2 dan tanpa DM tipe 2. Berdasarkan data yang diperoleh, terdapat 83 pasien tuberkulosis paru kasus baru yang menjalani rawat jalan di Poli Penyakit Dalam salah satu rumah sakit swasta Cikampek selama bulan April - September 2017. Dari jumlah tersebut terdapat 26 pasien tuberkulosis paru kasus baru yang juga didiagnosis menderita DM tipe 2. Distribusi pasien tuberkulosis paru kasus baru pada pasien DM tipe 2 adalah 31,33\%.

Tabel 2. Distribusi frekuensi pasien tuberkulosis paru kasus baru dengan DM tipe 2 yang menjalani rawat jalan di Poli Penyakit Dalam salah satu rumah sakit swasta Cikampek selama April - September 2017 menurut jenis kelamin

\begin{tabular}{lll}
\hline Jenis Kelamin & $\mathrm{n}$ & $\%$ \\
\hline Laki-laki & 12 & 46,15 \\
\hline Perempuan & 14 & 53,85 \\
\hline Total & 26 & 100 \\
\hline
\end{tabular}

Tabel 2 menunjukkan bahwa sebagian besar pasien tuberkulosis paru kasus baru dengan DM tipe 2 yang menjalani rawat jalan di Poli Penyakit Dalam salah satu rumah sakit swasta Cikampek selama April - September 2017 berjenis kelamin perempuan 14 orang $(53,85 \%)$, sedangkan pasien tuberkulosis paru kasus baru dengan DM tipe 2 yang berjenis kelamin laki-laki berjumlah 12 orang $(46,15 \%)$. 
Tabel 3. Distribusi frekuensi pasien tuberkulosis paru kasus baru dengan DM tipe 2 yang menjalani rawat jalan di Poli Penyakit Dalam salah satu rumah sakit swasta Cikampek selama April - September 2017 menurut usia

\begin{tabular}{lll}
\hline Usia (tahun) & $\mathrm{n}$ & $\%$ \\
\hline $36-54$ & 9 & 34,61 \\
\hline$>54$ & 17 & 65,39 \\
\hline Total & 26 & 100 \\
\hline
\end{tabular}

Data dari Tabel 3 memperlihatkan bahwa tuberkulosis paru kasus baru dengan DM tipe 2 yang menjalani rawat jalan di Poli Penyakit Dalam salah satu rumah sakit swasta Cikampek selama April - September 2017 terbanyak berasal dari kelompok usia >54 tahun yaitu 17 orang $(65,39 \%)$.

Tabel 4. Distribusi frekuensi tuberkulosis paru kasus baru dengan DM tipe 2 yang menjalani rawat jalan di Poli Penyakit Dalam salah satu rumah sakit swasta Cikampek selama April September 2017 menurut hasil pemeriksaan Basil Tahan Asam (BTA) sputum

\begin{tabular}{lll}
\hline Hasil Pemeriksaan BTA Sputum & $\mathrm{n}$ & $\%$ \\
\hline BTA (+) & 10 & 38,46 \\
\hline BTA (-) & 16 & 61,54 \\
\hline Total & 26 & 100 \\
\hline
\end{tabular}

Pada Tabel 4 dapat dilihat bahwa sebagian besar pasien tuberkulosis kasus baru dengan DM tipe 2 yang menjalani rawat jalan di Poli Penyakit Dalam salah satu rumah sakit swasta Cikampek selama April - September 2017 memiliki hasil pemeriksaan BTA sputum negatif yaitu sebanyak 16 pasien $(61,54 \%)$. Pasien tuberkulosis paru kasus baru dengan DM Tipe 2 BTA sputum positif $10(38,46 \%)$. 
Tabel 5. Distribusi frekuensi pasien tuberkulosis paru kasus baru dengan DM tipe 2 yang menjalani rawat jalan di Poli Penyakit Dalam salah satu rumah sakit swasta Cikampek selama April - September 2017 berdasarkan lamanya pengobatan yang dianjurkan

\begin{tabular}{lcl}
\hline Lama (bulan) & $\mathrm{n}$ & $\%$ \\
\hline$<8$ & 12 & 46,15 \\
\hline$>8$ & 14 & 53,85 \\
\hline Total & 26 & 100 \\
\hline
\end{tabular}

Pada Tabel 5 memperlihatkan bahwa insidensi tuberkulosis paru kasus baru dengan DM tipe 2 yang menjalani rawat jalan di Poli Penyakit Dalam salah satu rumah sakit swasta Cikampek sejak April - September 2017 berdasarkan lamanya pengobatan yang dianjurkan terbanyak selama $>8$ bulan yaitu 14 orang $(53,85 \%)$.

\section{Pembahasan}

Beberapa penelitian menunjukkan bahwa pasien TB dapat rentan terkena DM. Begitupun sebaliknya penderita DM juga rentan terkena TB. Distribusi pasien tuberkulosis paru kasus baru dengan DM tipe 2 yang menjalani rawat jalan di Poli Penyakit Dalam salah satu rumah sakit swasta Cikampek sejak April - September 2017sebanyak 26 pasien $(31,33 \%)$. Kemungkinan penyebab meningkatnya kejadian tuberkulosis paru pada penderita diabetes bisa jadi cacat pada pertahanan inang dan fungsi sel kekebalan tubuh. Kelainan kekebalan tubuh terutama melibatkan sel yang dimediasi oleh sel dari sistem kekebalan tubuh. Tingkat hiperglikemia juga telah ditemukan memiliki pengaruh yang berbeda pada fungsi mikrobisida makrofag, bahkan dengan paparan singkat pada kadar gula darah 200 mg\% secara signifikan menekan semburan pernapasan sel-sel ini (Guptan and Syah, 2000).

Namun, terdapat perbedaan antara DM tipe 1 dan DM tipe 2 hubungannya dengan penyakit tuberkulosis. Sebuah penelitian menunjukkan bahwa DM tipe 2 lebih rentan terhadap komplikasi dengan penyakit tuberkulosis. Penelitian yang dilakukan di Shanghai Pulmonary Hospital Cina selama 2 (dua) tahun (2008-2009) mencatat dari 2.141 pasien yang 
didiagnosis TB paru tardapat 203 pasien DM yang terdiri dari 196(96,6\%) DM tipe 2 dan hanya 7(3,4\%) DM tipe 1 (Xiao and Sugawara, 2009).

Beberapa penilitian juga menunjukkan bahwa pada penderita diabetes yang kurang terkontrol dengan kadar hemoglobin terglikasi tinggi dapat lebih memperburuk tuberkulosis. Beberapa kelainan fisiologis paru juga telah diamati pada penderita diabetes yang berkontribusi terhadap pembersihan dan penyebaran infeksi yang tertunda pada host. Infeksi dengan basil TB menyebabkan perubahan lebih lanjut pada sitokin, monosit-makrofag dan populasi sel CD4 / CD8. Keseimbangan T limfosit subset CD4 dan CD8 memainkan peran sentral dalam memodulasi pertahanan host terhadap mikobakteri dan memiliki pengaruh mendalam pada tingkat regresi TB paru aktif (Guptan and Syah, 2000).

Pada penelitian ini ditemukan lebih banyak pasien tuberkulosis paru kasus baru dengan DM tipe 2 yang menjalani rawat jalan di Poli Penyakit Dalam salah satu rumah sakit swasta Cikampek sejak April - September 2017 dengan jenis kelamin perempuan 14 (57,69\%) dibandingkan dengan laki-laki 12 (42,31\%). Secara kontradiksi berbagai penelitian menunjukkan bahwa rasio penderita berdasarkan gender (jenis kelamin) dapat berbeda berdasarkan latar belakang sosio-demografi, sosio-ekonomi dan waktu penelitian. Penelitian yang dilakukan Kusumawardhani (2015) di Rumah Sakit Paru Sidawangi Jawa Barat Periode Januari-Juni 2015 menunjukkan jenis kelamin perempuan lebih banyak. Dari total 126 pasien sebagian besar pasien memiliki jenis kelamin perempuan sebanyak 71 pasien (56\%) dan 55 pasien (44\%) laki-laki. Hal yang berbeda pada evaluasi penggunaan obat tuberkulosis pada pasien rawat inap di Ruang Perawatan Kelas III di salah satu Rumah Sakit di Bandung oleh Sukandar, Hartini, Hasna (2012) menunjukkan jumlah laki-laki 54 (62,79\%) lebih banyak dari wanita $32(37,21 \%)$.

Data Tabel 3 pada hasil penelitian ini ditemukan kasus tuberkulosis paru kasus baru dengan DM tipe 2 paling banyak terjadi pada usia lebih dari 54 tahun sebanyak 17 pasien $(65,39 \%)$, usia dimana mendekati 60 tahun tersebut menandakan adanya kecenderungan peningkatan insidensi TB paru pada DM seiring dengan meningkatnya usia. Hal ini sesuai dengan hasil penelitian sebelumnya yang menyatakan bahwa risiko terjadinya tuberkulosis pada pasien DM lebih besar pada usia yang lebih tua (Sanusi, 2006). Pada penelitian Guptan \& Shah (2000) disebutkan bahwa pasien yang paling banyak menderita DM tipe 2 dengan 
TB paru adalah pasien dengan kisaran umur di atas 40 tahunan. Hal ini terutama disebabkan karena dengan bertambahnya umur, fungsi sel pankreas dan sekresi insulin berkurang. Selain itu, kondisi hiperglikemia yang tidak terkontrol merupakan faktor predisposisi untuk timbulnya infeksi karena berkurangnya fungsi monosit makrofag (Soetedjo, F.A, 2009).

Demikian pula pada pasien usia lanjut lebih rentan untuk terkena infeksi $M$. tuberculosis. Hal ini disebabkan oleh ada perubahan biologis yang terjadi pada tubuh pasien, terutama pada jaringan paru, terkait dengan penuaan. Perubahan tersebut dapat merusak sistem barier dan mekanisme klirens mikrobial pada sistem pernafasan. Pasien usia lanjut juga lebih rentan mengalami malnutrisi. Hal tersebut berkontribusi dalam menurunnya respon imun seluler terhadap $M$. tuberculosis. Hiperglikemia yang semakin tidak terkontrol akibat fungsi sel beta yang lebih terganggu dan faktor kontrol yang tidak teratur pada usia lanjut dapat semakin mengganggu sistem imunitas tubuh sehingga juga menjadi penyebab tingginya prevalensi TB paru pada pasien DM usia lanjut (Sanusi, 2006).

Hasil penelitian sebagaimana pada Tabel 4 memperlihatkan bahwa sebagian besar pasien tuberkulosis paru kasus baru dengan DM tipe 2 memiliki hasil pemeriksaan BTA sputum negatif 16 pasien $(61,54 \%)$. Hasil ini sesuai dengan hasil penelitian sebelumnya yang menyatakan bahwa 70\% pasien DM dengan TB paru memiliki hasil pemeriksaan BTA sputum negatif, dan hanya 38,46\% yang hasil pemeriksaan BTA sputumnya positif (Kirani et al., 1998). Penelitian lain melaporkan bahwa dari 100 orang pasien DM di India, 27\% didiagnosis TB paru dengan BTA negatif dan hanya $6 \%$ yang didiagnosis TB paru dengan BTA positif. Ada penelitian lain yang melaporkan hasil yang berbeda, yaitu 65,9\% pasien DM dengan TB paru di RSUP H. Adam Malik Medan memiliki hasil positif pada pemeriksaan bakteriologi BTA sputumnya. Sedikitnya pasien yang hasil pemeriksaan BTA sputumnya positif pada penelitian ini dapat disebabkan karena sulitnya mendapatkan spesimen sputum pasien akibat pasien yang tidak dapat mengeluarkan dahak secara spontan (Soetedjo, F.A, 2009). Hal ini dapat disebabkan karena tingginya keterlibatan lobus paru bawah pada pasien TB paru dengan DM sehingga proses ekspektorasi menjadi kurang efisien (Sanusi, H, 2006; Nasution, 2007; Berger and Granada, 1974). Penelitian Tadar et al menemukan bahwa 37,2\% pasien TB paru dengan DM memiliki gambaran radiologis atipikal yang melibatkan lobus tengah dan bawah paru, keterlibatan lobus paru bawah tersebut sering 
disebabkan oleh perforasi transbronkial nodus limfe hilus paru sehingga infeksi menyebar ke jaringan paru di sekitarnya. Penelitian lainnya menyebutkan bahwa hal ini lebih disebabkan oleh peningkatan tekanan oksigen alveolar di lobus bawah paru akibat perubahan stuktur histologis dan fungsional jaringan paru yang sering terjadi pada pasien DM (Perez-Guzman et al., 2000).

Deteksi TB paru pada pasien DM dilakukan masih dengan metode standar yang dianjurkan untuk diagnosis TB yaitu dengan pemeriksaan sputum BTA ditambah pemeriksaan foto toraks. Deteksi TB pada pasien DM dengan mengandalkan klinis memiliki sensitifitas yang rendah. Pemeriksaan foto toraks memberikan hasil yang lebih baik akan tetapi memerlukan biaya yang lebih tinggi. Masih diperlukan penelitian untuk menentukan uji diagnosis yang tepat sekaligus biaya yang murah untuk skrening dua arah TB dan DM.

Lamanya pengobatan yang dianjurkan (lihat tabel 5), dimana hingga saat ini belum ada rekomendasi khusus pengobatan TB paru pada penderita DM. Regimen yang sama sesuai standar pengobatan TB paru tetap digunakan pada penderita TB paru disertai DM, tetapi akan lebih sulit dan bisa lebih lama hingga 12 bulan karena interaksi antara OAT (rifampisin) dan obat antidiabetes (sulfonilurea dan TZD), efek samping obat, dan jumlah bakteri lebih banyak. Insulin dapat digunakan untuk mengontrol kadar gula darah karena tidak terdapat interaksi dengan Obat Anti Tuberkulosis. Hal terpenting dan utama dalam keberhasilan pengobatan TB paru pada penderita DM adalah kontrol gula darah yang baik dan keteraturan minum Obat Anti Tuberkulosis (Wijaya, 2015).

Terkait hal tersebut di atas, belum ada rekomendasi kuat untuk memberikan panduan Obat Anti Tuberkulosis yang berbeda antara TB - DM dengan TB tanpa DM. Pasien TB dengan DM mendapatkan terapi standar sesuai dengan pasien TB lain yang hal ini sesuai dengan rekomendasi WHO. Perhimpunan Dokter Paru Indonesia (PDPI) pada panduan tentang TB-DM menyarankan hal yang sama dengan WHO dengan syarat gula darah terkontrol. Apabila kadar gula darah tidak terkontrol maka lama pengobatan dapat diperpanjang sampai dengan 9 bulan. Rifampisin sebagai OAT utama harus diperhatikan penggunaannya pada pasien TB dengan DM karena akan mengurangi efektifitas sulfonil urea dan biguanides sehingga dosisnya perlu ditingkatkan. Biasanya efek ini akan terlihat setelah 
dilakukannya terapi selama 1 minggu dan efeknya akan berkurang sampai menghilang setelah penghentian Rifampisin dalam waktu 2 minggu.

Penggunaan etambutol harus diawasi ketat terutama efek sampingnya pada mata, karena di sisi lain pasien dengan DM lebih sering mengalami komplikasi pada mata. Penggunaan INH juga harus dipantau oleh karena efek sampingnya yang akan menimbulkan neuropati perifer yang memungkinkan memberatnya keluhan neuropati yang telah ada pada pasien DM. Yang harus diperhatikan adalah bahwa seringkali hiperglikemia lebih sulit dikontrol selama TB masih aktif sehingga diperlukan penggunaan insulin untuk mengatasi hal ini. Penyebab pasti hal ini belum dapat dipastikan akan tetapi diduga sitokin inflamasi yang diproduksi seperti IL6 dan TNF $\alpha$ akibat infeksi TB akan meningkatkan resistensi insulin dan berkurangnya produksi insulin sehingga pada akhirnya akan mengakibatkan terjadinya hiperglikemia (Sanusi H, 2006; Niazi and Kalra, 2012; Baghei et al., 2015).

Tuberkulosis sering memperburuk kontrol gula darah dan membuat diabetes menjadi sulit untuk dikontrol. Penatalaksanaan DM pada pasien TB dengan DM harus dilakukan secara agresif. Tercapainya kontrol gula darah akan memberikan hasil akhir yang baik. Hal ini dapat dicapai melalui pemberian obat antidiabetes oral atapun insulin. Hal ini biasanya diawali dengan pemberian terapi insulin dengan insulin secara bolus atau insulin premixed. American Association of Clinical Endocrinologist merekomendasikan penggunaan insulin modern atau insulin analoque. Kebutuhan insulin dimulai dengan peningkatan dosis insulin dan kemudian secara perlahan diturunkan setelah gula darah terkontrol dalam beberapa minggu. Dosis insulin akan ditingkatkan kembali seiring dengan perbaikan nafsu makan menuju normal dan peningkatan asupan kalori.

Kadar gula yang diharapkan pada pasien TB dengan DM berkisar 120-150mg/dl. Kadar gula darah yang terkontrol membuat kerja Obat Anti Tuberkulosis menjadi lebih efektif dan perbaikan klinis serta radiologis yang lebih cepat pula. Untuk mencegah semakin memberatnya kedua penyakit maka deteksi dini terdapatnya DM pada pasien TB paru dan deteksi TB paru pada pasien DM merupakan cara yang dianjurkan WHO untuk kelompok yang berisiko untuk timbulnya TB. Pada penderita DM skrining TB menunjukkan tingkat kepositifan 1,7-37\% tergantung pada angka pevalensi TB dan beratnya DM. Sedangkan skrening DM pada penderita TB kepostifan berkisar 1,9-35\%. Diabetes mellitus secara klinis 
sulit dikenali pada pasien TB untuk itu perlu dilakukan pemeriksaan gula darah baik kadar gula darah sewaktu diikuti pemeriksasaan kadar gula darah puasa. Penelitian yang dilakukan di China dan India dengan melakukan pemeriksaan ini berhasil dideteksi DM pada 12-13\% pasien TB. Pemeriksaan kadar gula darah ini sebaiknya dilakukan setelah penderita mendapatkan terapi Obat Anti Tuberkulosis (Soetedja, FA, 2009; Baghei et al., 2015).

\section{KESIMPULAN}

Penelitian ini menunjukkan bahwa frekuensi DM Tipe 2 dengan TB paru kasus baru yang menjalani rawat jalan di Poli Penyakit Dalam salah satu rumah sakit swasta Cikampek selama April - September 2017 lebih banyak pada kelompok jenis kelamin perempuan $(53,85 \%)$, usia > 54 tahun $(65,39 \%)$, pemeriksaan BTA sputum negatif $(61,50 \%)$ dan lamanya pengobatan yang dianjurkan $>8$ bulan $(53,85 \%)$. Insidensi Tuberkulosis paru kasus baru pada pasien DM tipe 2 rawat jalan di Poli Penyakit Dalam di salah satu rumah sakit swasta Cikampek Kabupaten Karawang adalah sebesar 31,33\%.

\section{DAFTAR PUSTAKA}

Alisjahbana, B., van Crevel, R., Sahiratmadja, E., den Heijer M., and Maya, A., et al. 2006. Diabetes mellitus is strongly associated with tuberkulosis in indonesia. Int J Tuberc Lung Dis. 10(6), 696-700.

Baghei, P.T., Moniri, A.M.M., and Velayati, A.A. 2015. Impact of diabetes mellitus on tuberculosis drug resistance in new case tuberculosis. International Journal of Mycobacteriology, 4, 128.

Banu et al. 2006. Side effects due to primary antituberculosis drugs during the initial phase of therapy in 1149 hospitalized patients for tuberculosis. Journal Respiratory Medicine, 100, 1834-1842.

Berger, H.W., and Granada, M.G. 1974. Lower lung field tuberculosis. Chest, 65, 5.

Dale, D.C. 2003. Infectious Disease: The Clinician's Guide to Diagnosis, Treatment and Prevention. In. New York: WebMD Inc.

Ezung, T., Devi, N.T., Singh, N.T., and Singh, T.B. 2002. Pulmonary Tuberculosis and Diabetes Mellitus - a study. J Indian Med Assoc, 100, 376-9. 
Faurholt-Jepsen, M. 2011. Diabetes is risk factor for pulmonary tuberculosis: A case control study from Mwanza, Tanzania. Plos ONE, 6-8.

Girardi et al. 2017. The global dynamics of diabetes and tuberculosis: the impact of migration and policy implications; Review. International Journal of Infectious Diseases $56,45-53$.

Guptan and Syah. 2000. Tuberculosis and Diabetes: An Appraisal. Ind. J. Tub, 47, 3.

Kementerian Keseharan RI. 2014. Pedoman Nasional Pengendalian Tuberkulosis Direktorat Jenderal Pengendalian Penyakit dan Penyehatan Lingkungan.Kementerian Kesehatan Republik Indonesia.

Kirani K.R.L.S., Kumari, V.S., and Kumari RL. 1998. Co-existence of pulmonary tuberculosis and diabetes mellitus: some observations. Ind J Tub. 45-47.

Kottarath, M.D. et al. 2015. Prevalence of diabetes mellitus in tuberculosis patients: a hospital based study. Int J Res Med Sci, 3(10), 2810-2814.

Kusumawardhani. 2015. Evaluasi Penggunaan Obat Anti Tuberkulosis pada Pasein Rawat Jalan di Rumah Sakit Paru Sidawangi Jawa Barat Periode Januari-Juni 2015. Naskah Publikasi Karya Tulis Ilmiah. Fakultas Kedokteran dan Ilmu Kesehatan Universitas Mummadiyah Yogyakarta.

Moreira de Freitas, et al. 2015. Factors associated with knowledge about tuberculosis and attitudes of relatives of patients with the disease in Ribeirão Preto, São Paulo, Brazil. Rev. Bras Epidemiol, 18(2), 326-340.

Nasution, E.J.S. 2007. Profil penderita tuberkulosis paru dengan diabetes melitus dihubungkan dengan kadar gula darah puasa. Tesis. Fakultas Kedokteran Universitas Sumatera Utara. Medan.

Nazulis, R.A. 2011. Drug related problems pada pasien diabetes melitus tipe 2 dengan tuberkulosis paru di bangsal penyakit dalam dan poliklinik RSUP. Dr. M. Djamil Padang. Fakultas Kedokteran Universitas Andalas. Padang, 7.

Niazi, A.K., and Kalra, S. 2012. Diabetes and tuberculosis: a review of the role of optimal gycemic control. Journal of Diabetes and Metabolic Disorder, 11, 28-32.

Ottmani, S.E., Murray, M.B., Jeon, C.Y., Baker, M.A., Kapur, A., Lonroth, K., and Harries, A.D. 2010. Consultation meeting on tuberculosis and diabetes mellitus meeting summary and recomendation. Int J Tuberc Lung Dis. 14(12), 1513-7.

Perhimpunan Dokter Paru Indonesia (PDPI). 2011. Tuberkulosis. Pedoman diagnosis dan penatalaksanaan di Indonesia. Jakarta. Indah Offset Citra Grafika. 39-40. 
Perez-Guzman, C., Torres-Cruz, A., Villarreal-Velarde, H., and Vargas MH. 2000. Progressive age-related changes in pulmonary tuberculosis images and the effect of diabetes. American Journal of Respiratory and Critical Care Medicine, 162.

Sanusi, H. 2006. Diabetes melitus dan tuberkulosis paru. Jurnal Medika Nusantara, 25(1).

Soetedjo, F.A. 2009. Perbandingan kepekaan pemeriksaan kuman BTA dari dahak spontan dengan dahak induksi salin $0,9 \%$ pada akhir terapi fase intensif DOTS.

Suyono, S. 2011. Kecenderungan peningkatan jumlah penyandang diabetes. Penatalaksanaan diabetes melitus terpadu. Edisi ke-2. Jakarta: Balai Penerbitan Fakultas Kedokteran Universitas Indonesia, 6-22.

Tadar, D., Senol, G., Alptekin, S., Karakurum, C., Aydin, M., and Coskunol, I. 2009. Tuberculosis in diabetics: features in an endemic area. Jpn. J. Infect. Dis, 62, 423-7.

Wang, J., and Shen, H. 2009. Review of cigarette smocking and tuberculosis in China: intervention is needed for smocking cessation among tuberculosis patients. BMC Public Health, 9, 292.

World Health Organization. 2012. Gender and tuberculosis.

Xiao, Z and Sugawara. 2009. Tuberculosis Complicated by Diabetes Mellitus at Shanghai Pulmonary China, Jpn. J. Infect. Dis, 62, 390-391. 